\title{
A MIDIATIZAÇÃO DA VIOLÊNCIA ESCOLAR: O CENÁRIO DAS PRODUÇÕESACADÊMICAS
}

Lívia Sasada Silva*

Resumo: Este estudo busca contribuir para o estado do conhecimento daveiculação da violência escolar na mídia impressa e dos sentidos que lhe são atribuídos. 0 levantamento bibliográfico de trabalhos tais como teses e dissertaçoes, artigos e publicações em periódicos e eventos, obtidos em bases de dados diversas, permitiu perceber, sobretudo, a negligência do campo da educação na produção de conhecimento a respeito do tema em questão, dada a carência de investigações, o que, do contrário, possibilitaria uma melhor compreensão do tipo de influência que a mídia exerce so bre a sociedade e a comunidade escolar, ao propor sua percepção do fenômeno da violência e deste em relação à escola.

Palavras-chave: V iolência escolar. M ídia. Pesquisas. E ducação.

\section{MEDIATIZATION OF THE SCHOOL VIOLENCE : THE SCE NERY OF ACADE MIC PRODUCTIONS.}

Abstract: This study contributes to the state of the knowledge concerning the propagation of school violence in the press, and the meanings the latter assigns to school violence. Bibliographic research in works such as theses and dissertations, articles and publications, and academic events, gathered from several databases, made it possible to sense, mainly, the negligence in the field of education with respect to the production of knowledge on the subject in question, given the lack of researchwhich, otherwise, would allow for a better understanding of the kind of influence the media has on the society and the school community by means of the proposals of their perception of the phenomenon of violence, and of the latter in relation to the school setting.

Keywords: School violence. M edia. Research. Education.

* Especialista em Psicologia da Educação. Mestranda (Programa de Pós-Graduação em Educação, da U niversidade Federal do Pará). 


\section{INTRODUÇÃO}

A noticiabilidade da violência escolar na mídiaéum fenômeno razoavelmente recente que vem crescendo e tornando-se de domínio de toda a sociedade (ABRA M OVAY, 2002; 2003; DE BARBIEUX; BLAYA, 2002; FUNK, 2002; NAVARRO, 2003; ORTEGA, 2002; PONTES, 2007; SPOSITO, 2001). Os poucos estudos realizados sobre violência escolar, sua divulgação lacônica e restrita, aliados às posturas negligentes de muitas escolas (ABRA M OVAY, 2003; DE BARBIEUX; BLAYA, 2002; DA SILVA, 2010; FAN TE ; 2006) acabam por transferir à mídia, enquanto voz social, a responsabilidade pela divulgação das informações e casos sobre tal fenômeno. E sta última assume o papel de denunciadora e, a partir das suas próprias condições de produção das notícias, participa da constituição da "violência escolar" enquanto problema social merecedor de atenção, estudo e intervenção (ABRAM OVAY, 2003; DE BA RBIE UX; BLAYA, 2002; FUN K , 2002; ORTEGA. 2002; NAVARRO, 2003; IAURENS, 2006; LIMA, 2002a; 2002b; PIRES, 1985; SPOSITO, 2001).

Pensar sobre os sentidos que a mídia produz sobre a violência escolar, em Belém, é também considerar que, para além de uma concepção ingênua de mídia, apenas como agente social da informação, desinteressada e neutra, que apresenta os fatos tais como a realidade os cria; faz-se importante proceder à análise desse discurso midiático porquanto ideológico, imbuído de interesses e valores que, ao propor as notícias como o faz, expressa, sobretudo, uma tomada de posição perante as questões sociais (LIMA, 2002a; 2002b; LAURENS, 2006; CASTRO, 2002; RODRIGUES, 1980; BAKHTIN, 2009; WOLF, 1999). O que configura atitude cautelosa e justificável para uma melhor compreensão não só da violência escolar, mas, principalmente, do próprio funcionamento da mídia como articuladora de sentido e partícipe da construção da realidade social.

E m razão disto, questiona-se o campo de estudos da educação e da produção acadêmica, no sentido de lhe perceber as investigações já empreendidas acerca das significações que a mídia constrói na veiculação dos episódios de violência escolar, pela composição de um cenário que pudesse demonstrar a natureza das pesquisas desenvolvidas atualmente, no Brasil, sobre violência escolar, sobretudo no âmbito da abordagem da mídia - suas proposições, formatos, análises e descobertas já ef etuadas - de modo que essas também possam permitir lançar novos olhares, e outras demandas ainda não colocadas (ou pouco desenvolvidas), sobre os estudos da análise do discurso midiático na área da educação, subsidiando opções teóricometodológicas e abordagens mais consistentes a investigações posteriores.

Nesse sentido, aponta-se, a seguir, a trajetória teórico-metodológica que

160

Ver a E ducação, v. 12, n. 1, p. 159-182, jan./ jun. 2011 
norteia essa pesquisa, assim como as apreciações interpretativas dos dados e a apresentação dos resultados relacionados.

\section{O CENÁRIO DAS PRODUÇÕES NO DOMÍNIO DA ANÁLISE DO DISCURSO MIDIÁTICO SOBRE VIOLÊNCIA ESCOLAR}

Com a intenção de compor um cenário das produções no domínio da análise do discurso midiático, buscou-se o levantamento de trabalhos produzidos em programas de pós-graduação (teses e dissertações), por meio do banco de dados da Biblioteca Digital Brasileira de Teses e Dissertações (BDTD); dos grupos de pesquisa que se ocupam dessa abordagem, no diretório dos grupos de pesquisa do Conselho Nacional de Desenvolvimento Científico e Tecnológico (CNPq); dos periódicos disponiveis no banco de dados da Coordenação de Aperfeiçoamento de Pessoal do Ensino Superior (CAPES); e das publicações da Compós (Associação Nacional dos Programas de Pós-Graduação em Comunicação), em seus Grupos de Trabalho: Produção de Sentido e E studos de J ornalismo. A lém do levantamento realizado no campo de estudos diretamente voltados à violência escolar (nas mesmas bases de informações).

Tabela 1 - Amostra dos achados no campo próprio dos estudos sobre análise discursiva da mídia.

\begin{tabular}{c|c|c}
\hline \multirow{2}{*}{ Base de Dados } & $\mathbf{N}$ - de Trabalhos & $\mathbf{1 9 9 2 / 9 3}$ \\
\cline { 2 - 3 } & 46 & 222 \\
\hline \multirow{2}{*}{ BDTD } & Teses & Dissertações \\
\cline { 2 - 3 } & 10 & 36 \\
\hline GPS & \multicolumn{2}{|c}{14} \\
\hline Periódicos/ CAPES & \multicolumn{2}{|c}{13} \\
\hline COMPÓS & \multicolumn{2}{|c}{100} \\
\hline Total & \multicolumn{3}{|c}{} \\
\hline
\end{tabular}

Fonte: Construção da autora a partir dos achados nas bases de dados indicadas.

No que diz respeito à BDTD, que integra os sistemas de informação de teses e dissertações existentes em, aproximadamente, cem instituições de ensino e pesquisa brasileiras, foram encontrados quarenta e seis trabalhos sobre análise discursiva da mídia, entre Dissertações (36) e Teses (10). A maior concentração de trabalhos está na Região Sudeste (17), acompanhada da Região Centro-Oeste (12) e, em números menos expressivos, nas Regiões Sul (9) e Nordeste (8). A Pontifícia Universidade Católica de São Paulo (PUC-SP) lidera, com onze trabalhos encontrados. De maneira geral, as teses e dissertações que tratam da análise discursiva da mídia circunscrevem-se, predominantemente, à área da 
Linguística (21), seguida da área da Comunicação (14). Mas há extravasamento dessa preocupação para outras áreas, embora de maneira mais tímida - Ciências Sociais (3), Educação (3), Saúde Coletiva (2), Relações Internacionais (1), Ciências da Saúde (1) e Gerontologia (1).

No diretório dos grupos de pesquisa do $\mathrm{CNPq}$, encontraram-se quarenta e nove grupos de pesquisa (GP) que abordavam a temática que aqui interessa; mas em razão das dificuldades de acesso às produções, uma vez que muitos desses grupos não indicam endereço de homepageprópria, ou mesmo nos sítios de suas universidades, não as disponibilizam; trabalhamos com achados de apenas cinco grupos, e com alguns artigos de líderes de GP, os quais somam vinte e sete produções ao todo.

Levando em consideração o ano de formação desses GPs, podemos afirmar que as iniciativas nesse campo da análise do discurso midiático são bastante recentes, no Brasil, datando do início da década de 1990, e com apenas quatro composições de GPs nesse período. A Universidade Federal de Alagoas (UFAL) inaugura as discussões nesse campo, no país, com a formação do primeiro GP, em 1990, o que só voltaria a acontecer, em 1995, na Universidade Federal do Rio Grande do Sul (UFRGS). De 2000 a 2005, a média é de até três formações de GPs engajados em tal tipo de pesquisa e análise. No ano de2006, esse número eleva-se, consideravelmente, chegando a sete os GPs formados nesse ano, marca que só se alcança, novamente, em 2010. E ntre 2006 e 2011, a média é de, aproximadamente, cinco GPs constituídos com linhas de pesquisa nessa área.

De modo análogo ao que se percebe na análise das produções de teses e dissertações, em relação aos GPs, a maior concentração de produções está localizada também na Região Sudeste (16 GPs). Mas há, aqui, um diferencial, que é a quase equiparação à Região N ordeste, com quinze grupos de pesquisa. $\mathrm{A}$ U niversidade Federal da B ahia aparece com destaque, por reunir o maior número de GPs numa mesma instituição (4). O Sul do país agrega dez GPs, um número também bastante significativo, acompanhado do Centro-Oeste, com sete grupos. A Região Norte apresenta apenas um GP ocupado de tal temática, na Universidade do Tocantins (UN ITIN S).

A respeito das áreas de concentração sob as quais os GPs se formam, também não há muitas alterações: a Linguística desponta como área que subsidia a formação de trinta e dois desses GPs, seguida por Comunicação (13) e por iniciativas menores de áreas como a Educação (1), Ciência Política (3), História (1) e da E ducação Física (1).

Quanto ao banco de dados de periódicos da Capes, evidenciaram-se quatorze achados. D estes, sete são advindos da Região Sudeste, quatro da Região

162

Ver a E ducação, v. 12, n. 1, p. 159-182, jan./ jun. 2011 
Centro-Oeste, um, do Nordeste, e um, da Região Sul. Com base nisso, notouse que, apesar de a Região Sudeste aparecer, de certa forma, como expoente nos estudos sobre a análise discursiva da mídia (AD M ), o número de trabalhos publicados encontrados foi muito baixo. D e certo, está se ponderando que muitas dessas publicações não foram consideradas por tratarem da análise discursiva da publicidade e de outras mídias que não a impressa, cujas condições de produção são muito diversas entre si.

Mesmo considerando o corpus privilegiado - a busca de estudos sobre ADM impressa e eminentemente jornalística, o número de achados referentes à Região Sudeste em periódicos foi pequeno. Daí, pode-se abstrair pelo menos duas circunstâncias: a de que os trabalhos dessa Região, e mesmo das demais, concentrem-se mais na ADM publicitária e, ou, em outras mídias que não a impressa; e, ou, que a sua publicação se dê, na maior parte, em periódicos que não estejam vinculados ao banco de dados da Capes. A principal área produtora de estudos no campo da ADM impressa, nessa base de dados, foi a das Ciências da Saúde ${ }^{1}$, com cinco trabalhos; Letras, em seguida, com quatro, e, em menor frequência, Administração (1), Bioética e Direitos Humanos (1), História (1) e Psicologia (1).

Além das bases de dados já mencionadas acima, também se campearam trabalhos na COMPÓS. Por meio desta, alçaram-se treze achados congruentes aos interesses dessa pesquisa, entre os dois GTs - Produção de Sentido e Estudos de Jornalismo. D os treze trabalhos, seis são oriundos de universidades da Região Sudeste, três, da Sul, dois, da Nordeste, e um, da Região Centro-Oeste. Como se trata de um evento específico da área da Comunicação² é compreensível que o número maior de trabalhos viesse de esforços nessa área (10), mas ainda encontramos um trabalho da área de Letras e outro, da Sociologia.

De maneira geral, dentre os cem trabalhos encontrados, nas bases do diretório de grupos de pesquisa, periódicos (Capes), BDTD e da Compós; quarenta e três são oriundos da Região Sudeste, vinte e três, da Região Sul, dezenove, da Região Centro-Oeste, quatorze, da Região Nordeste, e nenhum, da Região Norte. 0 que nos leva a concluir que a Região Sudeste desponta em produção, no campo da ADM, muito embora haja proximidade entre as outras Regiões, exceto a Região N orte, que demonstra uma inexistência de trabalhos disponíveis nessas bases de dados, que pode, realmente, representar uma preocupante baixa produtividade ou apenas um reflexo da escolha dos espaços de busca.

Destacam-se as $\mathrm{PUC}^{3}$ e a UNB como as instituições representantes do maior número de trabalhos, vinte e um e onze, respectivamente. A sáreas de L etras (45) e de Comunicação (29) são as que mais se dedicam à ADM, muito embora, 
como já percebido na análise individual de cada base de dados, tal temática venha sendo objeto de outras áreas, como a de Ciências da Saúde (8) e, em proporções bem menores, a de E ducação (4).

O recorte temporal compreendido pelos achados está entre 1997 e 2011, demonstrando uma crescente no interesse pelo desenvolvimento de trabalhos no campo da ADM, is to porque, entre 1997 e 2004, a média é de dois a très trabalhos por ano; em 2005, alcança-se a marca de oito trabalhos apenas nesse ano, e chega a vinte e quatro, em 2010, de maneira que, entre 2005 e 2011, a média se aproxima de doze trabalhos publicados por ano.

No que diz respeito aos objetos e problemas levantados por essas produções, observou-se que existe certa relação de proximidade entre eles, o que permite agrupá-los sob um mesmo fim. Nesse sentido, é possivel destacar um grande número de trabalhos que investigam a forma como a mídia representa certos fatos sociais, o que se observa em Ghilardi (2010) e Swain (2001) sobre as relações de gênero; em Wandscheer (2008), sobre o crime organizado; Rodrigues e N ascimento (2010), sobre o sistema de cotas para negros; Lyra (2010), focalizando o Movimento dos Trabalhadores Rurais Sem Terra (MST); M orgado (2010), a educação; Caetano P. (2007), as relações raciais; Grigoletto (2005), estudando a divulgação científica; Assolini (2009), a sexualidade; Zanon (2009), o funk carioca; Leal (2005), as privatizações; Pereira, Macedo e Heins (2009), a Amazônia; Vieira e Pereira (2010), também a A mazônia; O liveira et al. (2010), pondo em foco a área da saúde; Tomita e Padula (2002), um acidente radioativo; e N jaine e M inayo (2002), rebeliões de jovens infratores.

O utros estudiosos apontam como a mídia representa certos sujeitos: os homens (gênero masculino), tema encontrado em Ghilardi-Lucena (2009) e Ghilardi (2005); as mulheres na política, em Gomes (2007), Morais (2008), e em Barbara e Gomes (2010); as mulheres como profissionais de um modo geral, em A ssumpção (2008); o corpo feminino, em Andrade (2002); jovens infratores, em Pedrosa (2008); pessoas com deficiência, em Silva M. C (2007); e ocupando-se da representação de índios, negros e meninos de rua, localizamos M artins (2005). A preocupação, nesses trabalhos, é apenas da descrição de tais representações, o que, às vezes, é acompanhada de questionamentos so bre se é justa ou não, porém não problematizam o porquê de a mídia o fazer como faz.

No que diz respeito a Machado R. (2007), Ferreira R. (2009), Ribeiro et al. (1998) e Tamanini-A dames (2010), pode-se dizer que, para além da preocupação do "como" a mídia representa fatos e, ou, sujeitos, eles também questionam seu conteúdo ideológico. Há, ainda, Ferreira J. (2010) e Frazão (2010) que se detêm da problematização quanto à participação dos cidadãos na construção discursiva da 
mídia, na representação de situações sofridas por eles, ou seja, do acesso que as pessoas têm à mídia para se expressar e expor seus pontos de vista. E o trabalho de Machado M. (2001), sobre a análise do discurso enquanto metodologia por excelência da análise do discurso midiático.

Outros estudos como o de Imbroisi (2009), Costa (2009), Medeiros (2010), Gomes (2010) e Silva L. M (2001) vêm tratando das condições de produção do discurso midiático; e os de Oliveira A. (2006), Silva S. (2007), Aguero (2008), Da Costa (2009), Corrêa et al. (2007), Mendes (2010), Dornelles (2002), Brusius (2002), Bernardes (2009), Gregolin (2007) e Tamanini-Adames (2010), que tratam da relação entre as produções de sentido da mídia e a construção de identidades / subjetividades. Há, ainda, os estudos de Barros (2010), Oliveira E. (2010), Benites (2009), L ameiras (2006), Rangel (2003), M aksud (2008), Barbosa (2008), B rito e Pasetti (2007), Fabrício (2005), Santos (2010), Kuwae (2006), e Henn (2005), que questionam se as representações feitas pela mídia existem, de fato, enquanto objeto material, ou são apenas construções discursivas da própria mídia.

O utro expressivo número de trabalhos dedicou-se a situar quais as estratégias discursivas utilizadas pela mídia para representar fatos e sujeitos, como é o caso de Silva L. S. (2008), Trindade (2007), Brito (2005), Silva M. (2008), Silveira e Passeti (2007), Silva M. C. F. (2011), Dalmonte (2010), Matheus (2009), Lima F. (2010), Campos (2010), Souza J. (2008), Assis (2010), Silva L.A. (2010), Bruggemann (2010), Cruz (2010), Ferreira L. (2007), Franciscato (2000), Amaral (2005), Peruzzolo (2001), Gonçalves e Melo (2010), Bueno (2008), Bonfin (2003), Camargo (2008), Ramalho (2005), Gregolin (2004), Guimarães (2006), Serra (2004), Serra e Santos (2003), Traquina (2000) e Caetano K. (2005).

$\mathrm{N}$ ão se encontrou nenhum trabalho que problematizasse a presença da violència escolar na mídia. Há estudos que buscam compreender as representações da violência na mídia, mas de uma violência que ou égenérica, como nos trabal hos de Dias (2008), Lisboa (2007) e Candiani (2007), ou é específica, como os de Garbin (2009), que problematiza a representação do assédio moral na mídia; os de Souza A . (2009) sobre a representação da violência com idosos; de Silva L. K . (2008) sobre o abuso sexual infanto-juvenil; os desenvolvidos por Souza L. (2009) sobre a cobertura de um caso específico sobre violência com criança; e por Ferraz (2000), que trata da representação da violência nas favelas do Rio de Janeiro.

No que concerne às metodologias e respectivas teorias utilizadas, há quarenta e quatro trabalhos que indicam a A nálisedbDiscurso baseada nos mais variados autores, como opção teórico-metodológica . O principal destaque é para a análise do discurso em Foucault, indicado em oito desses trabalhos, e para a análise do discurso em Pêcheux (6) e em Fairclough (5). 0 utros nomes são Bakhtin (2), 
Maingueneau (2), Charaudeau (2), Teun Van Djik (1), Ducrot (1), e ainda outros que desenvolvem anál ise conjugando teorias de mais de um autor: Foucault e Bakhtin (2), Spink e M edrado (2), Pêcheux e Floch (1), Bakhtin, D eleuzee M aingueneau (1), O rlandi e M aingueneau (1), M aingueneau eFoucault (1), Foucault, Pêcheux eF reda Idursky (1), Foucault, Bakhtin e Pêcheux (1), Bourdieu, Foucault e Charaudeau (1), Barros e Horlandes (1), e Fairclough e Charaudeau (1).

Há, ainda, pesquisas que anunciam a Análise Crítica do Discurso (5), cujas teorias de base ancoram-se em Fairclough (2), Van Dijk (1), Foucault (1), Teoria Feminista e Estudos Culturais (1). Outros que apontam a Análise Crítica e Sistêmico-Funcional (1), sob a teoria de Fairclough. 0 ito trabalhos desenvolvem suas análises por meio da Análise do Discurso Francesa, com a utilização de autores como Pêcheux (2), Foucault (1), Charaudeau e Orlandi (1), Maingueneau ef loch (1), e, curiosamente, um trabalho que considera juntamente com Foucault, Pêcheux, Maingueneau, Certeau e Orlandi, a teoria do filósofo russo Bakhtin. M erecem destaque outros dois trabalhos que anunciam a utilização da A nálise do D iscurso Franco-Brasileira.

Há um considerável número de trabalhos que consideram a análise do discurso e outros métodos, como: - a Análise do Discurso e Análise do Conteúdo (2), havendo um que aponta Bardin e outro que, além da de Bardin, também utiliza a teoria de Fairclough; - Análise do Discurso e Linguístico-Cognitiva (1), por Maingueneau; Charaudeau e Locof; e Turner; - Análise do Discurso e Semiótica (2), incluindo História Cultural; Barthes e Benveniste (1); e Fairclough; Bourdieu; Wacquant e Cress; e Van Dijk (1); - Análise estrutural do discurso, Análise SócioCrítica e Hermenêutica (1), com a Teoria Social de B. Jhon Thompson; - Análise Dialógica do Discurso, Análise Crítica do Discurso e Análise Linguística SistêmicoFuncional (1), por Fairclough e Bakhtin.

Há, também, três estudos que se dedicam somente à Análise de Conteúdo, a saber, Bardin (1), teoria do Jornalismo para a paz (1) e Abordagem Sociológica (1). E outros, somente à Análise Semiótica (8), que aparece descrita como: - Análise Semiótica (3), por Semprini e Floch (1); Landowski (1); e Bystrina (1); - Análise Semiótica Discursiva (4), trazendo Greimas (2); Lituano, Greimas e Algida (1);-e Análise Semiótica Cultural (1), com estudos de Bystrina.

E por último, alguns trabalhos que utilizam outros métodos: - Análise Texto-Verbal (1), por Fabiane M oreira; M aingueneau; e I van L ima; - I nterpretação Técnico-Científica (1), valendo-se da Teoria da Interpretação de Paul Ricoeur; - Análise Lexical (1), com a Teoria das Representações Sociais de Moscovici; - Gramática Sistêmico-Funcional (GSF) (3), trazendo Halliday; - Método Etnográfico (1), por Da Matta; - SPSS [Statistics Package for the Social Sciences]

166

Ver a E ducação, v. 12, n. 1, p. 159-182, jan./ jun. 2011 
tratando desse software de análise estatística. Além desses, nove trabalhos de Revisão Bibliográfica.

Sobre o recorte temporal, há trinta e quatro estudos que analisam apenas um ano de produção midiática sobre o objeto ao qual se dedicam; destes, um, apenas, faz levantamento na década de 1970; um, sobre a década de 1980; três, sobre a década de 1990; e vinte e nove trabalhos que levantam informações nos anos referentes às décadas de 2000 e 2010. 0 que nos leva a perceber que os trabal hos sobre análise do discurso midiático, privilegiam a compreensão dos discursos da contemporaneidade. 0 s perío dos mais extensos de análise são de três trabal hos de dissertação: um que investiga o corpus compreendido entre 1968-2005, um período de trinta e sete anos; outro, de 1968 a 2007 (39 anos); e o mais vasto, que considera um período de 40 anos. 0 s demais oscilam entre meses de um ano específico, dois anos, três anos, cinco anos, uma década, e anos intercalados em décadas diferentes.

De modo geral, é possivel perceber três compreensões sobre a produção de sentido da mídia, formadas a partir das conclusões dos estudos levantados. Uma seria a dos trabalhos que tomam a representação da mídia como reflexo do real e se limitam a descrevê-la, apenas para realçar certos pontos de vista sobre determinado objeto. Outra, a que percebe a mídia como aparelho ideológico que se utiliza as mais diversas estratégias discursivas para manter uma ordem hegemônica, e sob interesses de classe; e uma última, que entende a mídia como partícipe dos jogos discursivos, de produção de sentido e, consequentemente, de poder; que constrói sentido a partir de seu lugar próprio, de condições/estratégias que the são intrínsecas; que imbuídas de interesses e valores, se situam para além da informação imparcial; influenciando as pessoas na sua forma de compreender o mundo e de se constituir enquanto sujeito, porém não o determinando.

Do campo próprio dos estudos sobre violência escolar, os achados do levantamento empreendido permitiram a síntese apresentada na tabela a seguir.

Tabela 2 - Amostra dos achados campo próprio dos estudos sobre violência escolar.

\begin{tabular}{c|c|c}
\hline \multirow{2}{*}{ Base de D ados } & \multicolumn{2}{|c}{ No de Trabalhos } \\
\cline { 2 - 3 } & \multicolumn{2}{|c}{46} \\
\hline \multirow{2}{*}{ BDTD } & Teses & Dissertações \\
\cline { 2 - 3 } & 2 & 31 \\
\hline Grupos de Pesquisa & \multicolumn{2}{|c}{43} \\
\hline Periódicos & \multicolumn{2}{|c}{9} \\
\hline Busca Livre & \multicolumn{2}{|c}{6} \\
\hline Livros/Capítulos & 130 \\
\hline Total & \multicolumn{2}{|c}{. } \\
\hline
\end{tabular}

Fonte: Construção da autora a partir dos achados nas bases de dados indicadas. 
Faz-se relevante ressaltar que, dentre cento e trinta (130) trabalhos encontrados, apenas o trabalho de Laurens (2006) discute a relação entre 0 contexto de violência na realidade das escolas e a representação dessa violência na mídia. Trata-se de uma revisão bibliográfica, à revelia de análise documental e, ou, empírica do espaço escolar; tal autor o tece, sobretudo, baseado em articulação de fontes bibliográficas e, apesar de apontar alguns fatos que se tornaram notícias na mídia, não faz qualquer menção à pesquisa realizada, ou fontes. 0 que, da mesma forma, é realizado por D ebarbieux (2002) no livro "V iolência nas escolas: dez abordagens europeias", numa subseção do primeiro capítulo - 0 perigo da mídia - onde questiona a construção de uma falsa ideia de insegurança, proposta pela mídia, o que segundo tal autor, abre precedente para que o discurso da violência seja utilizado para o conservadorismo e a repressão. Ele adverte que as pesquisas, assim como a mídia, não deveriam tratar tal temática apenas como mais uma simples qualificação alternativa de novos episódios, sob uma ótica de curto prazo, mas evidenciá-la enquanto construto histórico-social que, como tal, não surge de repente.

D estarte, foi possível perceber que os maiores esforços de pesquisa sobre violência escolar estão concentrados na compreensão do fenômeno e da sua dinâmica no contexto escolar $(37,5 \%)$. Seguem-se trabalhos que se detêm na investigação de ações interventivas e preventivas desenvolvidas pelas escolas $(19 \%)$; e outros, que tratam das representações construídas por escolares acerca da violência escolar (14\%) e do papel dos pais e educadores mediante o fenômeno da violência $(11 \%)$. Em menor número, aparecem, também, estudos que vêm tratando dos possiveis determinantes da violência escolar $(6,5 \%)$; das relações entre as manifestações de violência na escola e questões de gênero (5\%); da questão da violência escolar em relação à saúde $(1 \%)$, tratada por um estudo; e outros que percorreram das políticas públicas de intervenção à violência nas escolas (4\%).

D entre as áreas do conhecimento que se ocupam da violência escolar, destacam-se a Educação, as Ciências Sociais e a Psicologia, como áreas que demonstram uma expressividade maior em relação ao desenvolvimento de trabalhos com essa abordagem; apesar de outras também aparecerem nesse contexto, ainda que com menor impacto, tais como o Serviço Social e a Teologia, por exemplo. A partir desse panorama, é possível evidenciar que o debatea respeito da violência escolar é uma questão que não tem se limitado apenas à E ducação, apesar da predominância dos estudos nessa área, mas que outros profissionais também têm se dedicado a pensar esse fenômeno, que é complexo em si mesmo, exigindo ações articuladas e transdisciplinares no seu trato.

168

Ver a E ducação, v. 12, n. 1, p. 159-182, jan./ jun. 2011 
Mas apesar desse amplo esforço de produção de conhecimento na área, no que diz respeito às apreensões acerca das representações que a mídia tece sobre a violência escolar; estas têm se destacado como estudos apenas de áreas outras que não a E ducação, apesar de as notícias a respeito da violência escolar serem recorrentes na mídia, o que deveria estar impulsionando curiosidades epistemológicas de compreensão do seu papel como difusora (também) dessa temática, de modo que pudesse ser objeto de reflexão na agenda das escolas e por pesquisadores da E ducação.

O utro destaque pertinente está para a quase inexistente atuação de pesquisadores da Região N orte nesse contexto de investigação. Pois, apesar de a violência perpassar contextos midiáticos diversos e indistintamente, os focos das pesquisas mostram-se concentrados nas Regiões Sul e Sudeste, o que é intrigante, uma vez que somente essas Regiốes têm merecido destaque enquanto produtoras e lócus de pesquisa. Há a emergència de trabalhos que discutem as singularidades culturais e educacionais amazônidas em suas manifestações midiáticas, de maneira a se fazerem conhecer não só os processos de construção da opinião pública sobre certos fenômenos sociais, como a violência escolar, mas também para inseri-la de forma mais contundente no contexto maior das iniciativas de produção de conhecimento.

\section{CONSIDERACOOES FINAIS}

Os esforços empreendidos no levantamento de tais trabalhos de pesquisa foram de imprescindível importância para a compreensão do campo de pesquisa sobre violência escolar na mídia; ou melhor, do quanto essatemáticanão tem estado nas agendas de pesquisa. M uito embora a mídia esteja continuamente construindo uma imagem sociocultural da escola, ao publicizar a violência escolar em suas manchetes, as pesquisas continuam alheias à problematização de tais significações empreendidas pela mídia, acerca das escolas brasileiras e seus contextos.

D estacamos, dessa forma, o quanto o campo que se detém na pesquisa sobre a violência escolar é insipiente de estudos que possam traduzi-la para que haja compreensão de suas dimensões histórico-culturais, principalmente, em relação à forma pela qual a mídia tem construído significados sociais acerca desse tema, influenciando, muitas vezes, a forma pela qual as pessoas estabelecem suas condutas perante os eventos de natureza violenta e para a qual o arcabouço documental estaria em privilégio. Pois a grande maioria dos trabalhos tem se ocupado da dinâmica do fenômeno na escola, sem a compreensão de como os 
sujeitos escolares e, de maneira ampla, os sujeitos sociais significam o fenômeno, o que implica diretamente a forma como esses se comportam perante tais situações.

Desse espectro de abordagens e concepções de todo um campo de estudos sobre a produção de sentido e da análise do discurso midiático, é que reiteramos a pertinência de um estudo que considere a mídia como partícipe da construção de certa imagem da violência escolar, na cidade de Belém, e como vetor privilegiado dessas informações. E que, levando em consideração que há um grande esforço para a compreensão do fenômeno da violência escolar, talvez seja tempo de considerar seus significados no âmbito da sua veiculação.

\section{REFEREANCIAS}

ABRAMOVAY, Miriam. Violència na escola: América Latina e Caribe. Brasília: UNESCO, 2003.

ABRAMOVAY, Miriam et alii. Violências nas escolas. Brasilia: UNESCO Brasil, REDE PITÁGORAS, Coordenação DST/AIDS do Ministério da Saúde, a Secretaria de Estado dos Direitos Humanos do Ministério da Justiça, CNPq, Instituto Ayrton Senna, UNAIDS, Banco Mundial, USAID, Fundação Ford, CONSED, UNDIME, 2002.

AGUERO, Rosemere de A. A construção do discurso sobre o trabalho infantil: mídia, imagens e poder. 2008. 146 f. D issertação (M estrado em Letras) - Universidade Federal de Mato Grosso do Sul. Três Lagoas (MS), 2008. Disponível em: <http://www.cbc.ufms.br/tedesimplificado/tde_busca/arquivo. php?cod Arquivo=374>. Acesso em: 14 fev. 2011.

A M A RA L, M árcia Franz. Sensacional ismo, um conceito errante. E ncontro A nual da Associação Nacional de Pós-Graduação em Comunicação (Compós), 14. 2005. Niterói. ANAIS [eletrônicos]. Compós, 2005. Disponível em: <http://www. compos.org.br/data/biblioteca_848.pdf>. Acesso em: 18 fev. 2011.

ANDRADE, Sandra dos Santos. Uma boa forma de ser feliz: representações de corpo feminino na revista Boa Forma. 2002. 139 f. D issertação (M estrado em Educação) - Universidade Federal do Rio Grande do Sul. Porto Alegre (RS), 2002. D isponível em: <http:/ / bdtd.ibict.br; http:/ / www.lume.ufrgs.br/ handle/10183/1623>. Acesso em: 14 fev. 2011.

ASSIS, Edjane Gomes de. Veja, Isto É e Época: recontando a I Iistória no universo midiático. 2010. 186 f. Tese (D outorado em Letras) - Universidade Federal da Paraíba. João Pessoa (PB), 2010. D isponível em: <http:/ / bdtd.biblioteca.ufpb.br/ tde_busca/arquivo.php?codArquivo=911>. Acesso em: 14 fev. 2011.

ASSOLINI, Rita de Cássia S. T. Adolescência e sexualidade: uma análise do discurso da mídia segmentada. 2009. 141 f. Dissertação (Mestrado em Comunicação)

170

Ver a E ducação, v. 12, n. 1, p. 159-182, jan./ jun. 2011 
- Universidade Metodista de São Paulo. São Bernardo do Campo (SP), 2009. Disponivel em: $<$ http://ibict.metodista.br/tedeSimplificado/tde_busca/arquivo. phprodArquivo=2026> Acesso em: 14 fev. 2011.

ASSUMPÇÃO, Márcia. As representações de mulher profissional brasileira e norte-americana construidas pela mídia impressa. 2008. 147 f. Dissertação (Mestrado em Letras) - Pontificia Universidade Católica de São Paulo. São Paulo, 2008. Disponivel em: <http://www.sapientia.pucsp.br//tde_busca/arquivo. phprcodArquivo=7871>. Acesso em: 14 fev. 2011.

BAKHTIN, Mikhail. Marxismo e filosofia da linguagem. São Paulo: Hucitec, 2009.

BARBARA, Leila; GOMES, Maria Carmen A.. A representação de Dilma Rousseff pela mídia impressa brasileira: analisando os processos verbais. Letras, Santa M aria, v. 20, n. 40 , p. $67-92$, jan./jun. 2010.

BARBOSA, Romilda M. de Souza. "Garota de Programa": acontecimento discursivo. 2008. 112 f. D issertação (M estrado em L etras) - U niversidade Federal de Mato Grosso do Sul. Campo Grande (MS), 2008. Disponivel em: <http:// www.cbc.ufms.br/tedesimplificado/tde_busca/arquivo.php?cod Arquivo $=225>$. A cesso em: 14 fev. 2011.

BARROS, E duardo Paes de. A construção do sucesso na Revista Veja. 2010. 132 f. Dissertação (Mestrado em Comunicação e Semiótica) - Pontificia Lniversidade Católica de São Paulo. São Paulo, 2010. Disponivel em: <http://www.sapientia. pucsp.br//tde_busca/arquivo.php?cod Arquivo=10942>. Acesso em: 14 fev. 2011.

BENITES, Sônia Aparecida L. A face do Brasil mostrada nas citações da Revista VEJA. Polifonia. Cuiabá (MT), 11.19, p. 1-28, 2009.

BERNARDES, Walkyria Wetter. A constituição identitária feminina no cenário político brasileiro pelo discurso midiático globalizado: uma abordagem discursiva crítica. 2009. 228 f. Tese (D outorado em Linguística) - U niversidade de B rasília, Brasilia, 2009. Disponivel em: <http://bdtd.bce.unb.br/tedesimplificado/tde_ busca/arquivo.php?cod Arquivo=5508>. Acesso em: 14 fev. 2011.

BONFIN, Jonilda Ribeiro. Reprodução assistida, bioética e discurso científico: estratégias discursivas da Revista Veja nos anos 2001 e 2002. 2003. 167 f. Dissertação (Mestrado em Ciências da Saúde) - Universidade de Brasilia. Brasília (DF), 2003. Disponivel em: <http://bdtd.bce.unb.br/tedesimplificado/tde_busca/arquivo. php? codArquivo=2227>. Acesso em: 14 fev. 2011.

BRITTO, Patrícia D uarte de. 0 discurso relatado enquanto estratégia linguística para construção e produção de sentidos no texto jornalístico. In: Congresso Nacional de Linguagens em Interação (CONALI), 1. 2007, Maringá. ANAIS. Maringá: Universidade Estadual de Maringá, 2007, p. 462-471.

BRITO, Patrícia Duarte de; PASSETTI, Maria Célia Cortêz. A (des)construção representacional do Partido dos Trabalhadores na Revista Veja. E ntretextos (UE L), v. 7, p. 84-97, 2007. 
BRUGGEMANN, Ângelo Luiz et al. Registros da copa de 2014 na cobertura da Folha de São Paulo sobre a copa da África do sul: reflexões preliminares de pesquisa em desenvolvimento. In: Congresso Sul brasileiro de Ciências do Esporte, 5. 2010. Itajaí. ANAIS. Itajaí (SC): UNIVALI, 2010. Disponível em:

<http:/ / www.rbceonline.org.br/ congressos/ index.php/ sulbrasileiro/ vcsbce/ paper/viewFile/2024/1108>. Acesso em: 18 fev. 2011

BRUSIUS, Fernanda K ist. M ídia e identidade: os catadores de materiais recicláveis nos jornais de Santa Maria. 2010. 121 f. Dissertação (Mestrado em Comunicação) - U niversidade Federal de Santa M aria. Santa M aria (RS), 2010. D isponível em: $<$ http://cascavel.cpd.ufsm.br/tede/tde_busca/arquivo.php?codArquivo=3203>. A cesso em: 14 fev. 2011.

BUE N O, V inicius Prates da Fonseca. 0 capital dá a palavra: um estudo do discurso da responsabilidade social na revista B rasil Sustentável. 2008. 100 f. D issertação (Mestrado em Comunicação Social) - Universidade Metodista de São Paulo. São Bernardo do Campo (SP), 2008. Disponivel em: <http://ibict.metodista.br/ tedeSimplificado/tde_busca/arquivo.php?cod Arquivo $=1560>$. Acesso em: 14 fev. 2011.

CAETANO, Kati. A aventura fotográfica partilhada: modos de olhar. Encontro Anual da Associação Nacional de Pós-Graduação em Comunicação (Compós), 14. 2005. Niterói (RJ). ANAIS [eletrônicos]. Compós, 2005. Disponivel em: $<$ http:// www.compos.org.br/data/biblioteca_882.pdf>. Acesso em: 15 de fev. 2011.

CAETANO, Paulo Henrique. A palavra-chave 'racismo' e suas relações lexicais: uma análise crítica dos discursos sobre relações raciais brasileiras em corpus de jornal impresso. 2007. 261 f. Tese (Doutorado em Linguística Aplicada) Universidade Federal de Minas Gerais. Belo Horizonte (MG), 2007. Disponivel em: <http:/ / www.bibliotecadigital.ufmg.br/ dspace/ bitstream/ 1843/ A LD R73WR4F/1/tese_paulo_caetano_completa.pdf>. Acesso em: 14 fev. 2011.

CAMARGO, Júlia Faria. Ecos do Fragor: a invasão do Iraque em 2003. A mídia internacional e a imprensa brasileira. 2008. 142 f. D issertação (M estrado em Relações Internacionais) - Universidade de Brasília. Brasília (DF), 2008. Disponivel em: <http://bdtd.bce.unb.br/tedesimplificado/tde_busca/arquivo. php?codArquivo=3671>. Acesso em: 14 fev. 2011.

CAMPOS, Carla Leila Oliveira. Estratégias de referenciação no discurso midiático - práticas ideológicas de inclusão e exclusão de dizeres no discurso sobre a guerra. Linguagem em (Dis)curso, Palhoça, SC, v. 10, n. 1, p. 43-67, jan./abr. 2010. Disponivel em: <http://www.scielo.br/pdf/ld/v10n1/v10n1a03.pdf>. Acesso em: 18 fev. 2011.

CANDIANI, Heci Regina. A mensagem recalcada: o mal-estar cultural em textos jornalísticos sobre violência. 2007. 237 f. Dissertação (Mestrado em Ciências Sociais) - Pontifícia Universidade Católica de São Paulo. São Paulo,

172

Ver a E ducação, v. 12, n. 1, p. 159-182, jan./ jun. 2011 
2007. Disponivel em: <http://www.sapientia.pucsp.br//tde_busca/arquivo. php? codArquivo=5770>. Acesso em: 14 fev. 2011.

CASTRO, Mary Garcia. O que dizem as pesquisas da Unesco sobre juventudes no Brasil: leituras singulares. In: N OVAE S, Regina Reys; PORTO, M arta; HENRIQUES, Ricardo (Org.). Juventude, Cultura e Cidadania. Rio de Janeiro, v.21, Ed. Especial, p, 63-90, 2002. (Comunicações do ISER).

CORREAA, Alessandra M. H. et. al. Soldadinhos-de-chumbo e bonecas: representações sociais do masculino e feminino em jornais de empresas. $\mathrm{RAC}-$ Revista de Administração Contemporânea, Rio de Janeiro, v. 11, n.2, p. 191-211, abr./jun.2007. Disponível em: <http://www.scielo.br/pdf/rac/v11n2/a11v11n2. pdf>. Acesso em: 18 fev. 2011.

COSTA, Deyvisson Pereira da. Corporeidades em tempos de biopoder: o discurso midiático sobre o cuidado com o corpo. 2009. 115 f. D issertação (M estrado em Comunicação e Biblioteconomia) - Universidade Federal de Goiás. Goiânia (GO), 2009. Disponível em: <http://bdtd.ufg.br/tedesimplificado/tde_busca/arquivo. phprcodArquivo=685>. Acesso em: 14 fev. 2011.

COSTA, Lucas Mendes Falcão. As astúcias de um destinador na Geleia Geral brasileira. 2009. 111 f. Dissertação (Mestrado em Comunicação e Semiótica) Pontifícia Universidade Católica de São Paulo. São Paulo, 2009. Disponível em: $<$ http://www.sapientia.pucsp.br//tde_busca/arquivo.phprcodArquivo=10242>. A cesso em: 14 fev. 2011.

CRUZ, Guilherme Amorim de Moraes et al. Olimpiadas Rio-2016: um estudo na mídia impressa sergipana. In: Congresso Sul-brasileiro de Ciências do Esporte, 5. 2010. Itajaí. ANAIS. Itajaí (SC): UNIVALI, 2010. Disponível em:

<http:/ / www.rbceonline.org.br/ congressos/ index.php/ sulbrasileiro/ vcsbce/ paper/viewFile/2141/1015>. Acesso em: 18 fev. 2011.

DALMONTE, Edson Fernando. Presente: 0 tempo do jornalismo e seus desdobramentos. História [online], v.29.n.1, p.328-344, 2010. Disponível em: <http://www.scielo.br/pdf/his/v29n1/19.pdf>. Acesso em: 18 fev. 2011

DEBARBIEUX, Éric; BLAYA, Catherine (Org.). Violência nas escolas: dez abordagens eutopeias. Brasília: UNESCO, 2002.

DIAS, Ana Rosa Ferreira. 0 discurso da violência: as marcas da oralidade no jornalismo popular. 3. ed. São Paulo: Cortez, 2008. 181 p.

DORNELLES, Leni Vieira. Meninas do papel. 2002. 175 f. Tese (Doutorado em Educação) - Universidade Federal do Rio Grande do Sul. Porto Alegre (RS), 2002. Disponível em: <http:/ /wwwlume.ufrgs.br/handle/10183/1645>. Acesso em: 14 fev. 2011

FABRICIO, Branca Falabella. Mulheres emocionalmente descontroladas: identidades generificadas na mídia contemporânea. DELTA. São Paulo, v. 20, 11. 2, p. 235-263, 
dez.2004. Disponível em: <http://www.scielo.br/scielo.phprscript=sci_arttext\&p id=S0102-44502004000200003 > . Acesso em: 18 fev. 2011.

FERRAZ, Sonia Maria Taddei. A mídia no combate à violência: a operação Rio. Favelados e favela como os bodes expiatórios. In: Fncontro Anual das Associações dos Programas de Pós Graduação em Comunicação (Compós), 9. 2000. Porto Alegre (RS). ANAIS. Porto Alegre (RS): FAMECOS-PUCRS, 2000. CD-ROM (Lista 6). D isponível em: <http:/ / www.compos.org.br; http:/ / www.compos.org. br/data/biblioteca_1392.pdf>. Acesso em: 18 fev. 2011.

FERREIRA JÚNIOR, Arnaldo Alves. A notícia como discurso: a cidadania representada pela mídia impressa no acidente radioativo de Goiânia. 2010. 95 f. Dissertação (Mestrado em Comunicação) - Universidade Federal de Goiás. Goiânia (GO), 2010. Disponível em: < http://bdtd.ufg.br/tedesimplificado/tde_busca/ arquivo.phprcodArquivo=1593>. Acesso em: 14 fev. 2011

FERREIRA, Luzmara Curcino. "A política em close": análise discursiva de algumas representações do leitor de VEJA. Estudos Linguísticos. São Paulo, v.36, n.3, p. 55-64, set./dez.2007. Disponível em: <http://www.gel.org.br/estudoslinguisticos/ edicoesanteriores/4publica-estudos-2007/sistema06/81.PDF>. Acesso em: 18 fev. 2011.

FE RRE IRA, Renata de A raújo. 0 controle da publicidade dealimentos na imprensa brasileira: uma análise de artigos publicados em jornais. 2009. 79 f. Dissertação (Mestrado em Saúde Coletiva) - Universidade Federal da Bahia. Salvador (BA), 2009. Disponível em: <http:/ www.bibliotecadigital.ufba.br/tde_busca/arquivo. phpicodArquivo=2477>. Acesso em: 14 fev. 2011.

FRANCISCATO, Carlos Eduardo. A atualidade no Jornalismo. In: FAUSTO NETO, A ntonio et al. (O rg.). Práticas midiáticas e espaço público. Porto Alegre: EDIPLCRS, 2001, p. 261-289.

FRAZÄO, Theresa Christina Jardim. O morador de rua e a invisibilidade do sujeito no discurso jornalístico. 2010. 263 f. Tese (D outorado em Linguística) Universidade de B rasília, Brasília, 2010. D isponível em: <http:/ / bdtd.bce.unb. $\mathrm{br} /$ tedesimplificado/tde_busca/arquivo.php?codArquivo=6993>. Acesso em: 14 fev 2011.

FUNK, Walter. A violência nas escolas alemãs - situação atual. In: DEBARBIEUX, Éric; BLAYA, Catherine (Org.). Violência nas escolas: dez abordagens europeias. Brasilia: UNESCO, 2002, p.131-152.

GARBIN, Andréia de Conto. Representações na mídia impressa sobre o assédio moral no trabalho. 2009. 169 f. D issertação (M estrado em Saúde Pública) - Universidade de São Paulo, Faculdade de Saúde Pública. São Paulo, 2009. D isponível em: <http:/ / www.teses.usp.br/ teses/ disponiveis/ 6/ 6134/ tde21092009-145221/pt-br.php>. Acesso em: 14 fev. 2011.

GHILARDI-LUCENA, Maria Inês. Representações do gênero masculino na

174

Ver a E ducação, v. 12, n. 1, p. 159-182, jan./ jun. 2011 
mídia impressa brasileira. Congresso da Associação Portuguesa de Ciências da Comunicação (SOPCOM), 4. 2005. Aveiro. Livro de Actas. Aveiro (PT), 2005, v. 1, p. 1018-1025. D isponível em: <http:/ / www.bocc.ubi.pt/ pag/ ghilardi-mariarepresentacoes-genero-masculino-midia-imprensa-brasileira.pdf $>$. Acesso em: 18 fev. 2011.

Representações de gênero social na mídia. Web-revista Discursividade E studos Linguísticos, M aringá (PR), v. 6, jul.-dez. 2010. D isponível em: <http:/ / www.discursividade.cepad net.br/EDICOFS/06/Arquivos/LUCENA.pdf>. A cesso em: 18 fev. 2011.

GIIILARDI-LUCENA, Maria Inês; LUCENA, Tamires Nascimento. Discurso e gênero: imagens da beleza masculina. Encontro de Iniciação Científica da PUCCampinas, 14. 2009. Campinas. AN AIS [online]. Disponível em: <http://www. puc-campinas.edu.br/pesquisa/ic/pic2009/resumos/\%7B6C40DFAE-BF0546A4-A14B-F1A54B97F461\%7D.pdf>. Acesso em: 18 fev. 11.

GOMES, Maria Carmen Aires. Mulheres e política: analisando a representação sociocultural midiática. Linguagem em (Dis)curso, Tubarão (SC), v. 7, n. 2, p. 195 214, maio/ago. 2007. Disponível em: <http://www3.unisul.br/paginas/ensino/ pos/linguagem/0702/4\%20\%20art\%202.pdf>. Acesso em: 18 fev. 2011.

Ação social midiatizada: analisando a recontextualização de um evento social. Linguagem em (Dis)curso Impresso], Palhoça (SC), v. 10, 1. 2, p. 293-313, maio/ ago. 2010. D isponível em: <http:/ / www.scielo.br/ pdf/ ld/ v10n2/ v10n2a04. pdf>. Acesso em: 18 fev. 2011.

GONÇALVE, Gisele Siqueira; MELO, Mônica Santos de Souza. A representação dos adolescentes pelo jornalismo através da linguagem gíria observada na Todateen. In: Congresso de Cièncias da Comunicação da Região Sudeste (Intercom), 15. 2010, Vitória. ANAIS. Vitória: Intercom; UFES, 2010, v. 1, p. 1-14. Disponível em: <http://www.intercom.org.br/sis/regional/resumos/R19-0848-1.pdf>. A cesso em: 18 fev. 2011.

GREGOLIN, Maria do Rosário Valencise. Os sentidos na mídia: rastros da história na guerra das cores. Linguagem: Estudos e Pesquisas, Catalão (GO), v. 1, n. 4-5, p. 11-30, 2004. D isponível em: <http:/ / www.revistas.ufg.br/ index.php/ lep/ article/ view/12047/8008>. Acesso em: 18 fev. 2011.

. Análise do discurso e mídia: a (re) produção de identidades. Comunicação, Mídia e Consumo. São Paulo, v. 4, n.11, p. 11-25 , nov. 2007. Disponível em: $<$ http://revistacmc.espm.br/index.php/revistacmc/article/view/117/118>. A cesso em: 18 fev. 2011.

GRIGOLETTO, Evandra. O discurso de divulgação científica: um espaço discursivo intervalar. 2005. 269 f. Tese (D outorado em Letras) - Universidade Federal do Rio Grande do Sul, Porto Alegre, 2005. Disponivel em: $<$ http://www. lume.ufrgs.br/handle/10183/5322>. Acesso em: 14 fev. 2011. 
GUTMARÃES, Luciano. O repertório dinâmico das cores na mídia: produção de sentido no jornalismo visual. In: E ncontro A nual da A ssociação N acional dos Programas de Pós-Graduação em Comunicação (Compós), 15. 2006, Bauru (SP). AN AIS [eletrônicos]. Compós, 2006. Disponível em: $<$ http://www.compos.org. br/data/biblioteca_504.pdf>. Acesso em: 18 fev. 2011.

IIENN, Ronaldo C. et al. Notícias: dos crimes às transmutações de sentido. In: Encontro Anual da Associação Nacional dos Programas de Pós-Graduação em Comunicação (Compós), 14. 2005, Niterói. ANAIS [eletrônicos]. Compós, 2005. Disponivel em: <http://www.compos.org.br/data/biblioteca_844.pdf >. Acesso em: 18 fev. 2011.

IMBROISI, Françoise. Atos de fingir ou o caráter ficcional no fotojornalismo brasileiro. In: Encontro A nual da Associação N acional dos Programas de Pós-Graduação em Comunicação (Compós), 18. 2009. Belo Horizonte (MG). ANAIS [eletrônicos]. Compós, 2009. In: <http://www.compos.org.br/data/ biblioteca_1127.pdf>. Acesso em: 18 fev. 2011.

KUWAE, Luiza Hiroko Yamada. O papel da mídia na construção social do escândalo político. 2006. 152f. D issertação (Mestrado em Linguística) Universidade de Brasília, Brasília, 2006. Disponível em: <http:/ / bdtd.bce.unb. $\mathrm{br} /$ tedesimplificado/tde_busca/arquivo.php?cod Arquivo=701>. Acesso em: 14 fev. 2011.

LA M E IRA S, M aria Stela T. B. E ntre os contos de uma posse e o poder da palavra: "ligações perigosas" entre a mídia, a palavra e o poder político. 2006. $227 \mathrm{f}$. Tese (Doutorado em Linguística) - Universidade Federal de Alagoas. Maceió, 2006. Disponível em: $<\mathrm{http}: / /$ bdtd.ufal.br/tde_busca/arquivo.php?cod Arquivo=235>. A cesso em: 14 fev. 2011.

LAURENS, Jean-Paul. A violência escolar entre mídia e realidade. Revista FAMECOS. Porto Alegre, n 29, abril, 2006. Disponível em: <http://wwwrrevistas. univerciencia.org/index.php/famecos/article/view/471/398>. Acesso em: 18 fev. 2011.

LEAL, Maria Christina Diniz. O discurso jornalístico sobre privatizações e protestos nas ruas. DELTA. São Paulo, v. 21, n. especial., p. 73-92, 2005. Disponível em: $<$ http://www.scielo.br/pdf/delta/v21nspe/29252.pdf>. Acesso em 18 fev. 2011.

LIMA, Fernanda Fernandes P. de A.. Entre o diálogo e a (re) significação do sentido: um olhar sobre a identidade da mulher política. Bakhtiniana. São Paulo, v.1, n. 3, p. 99-112, 1.sem. 2010. D isponível em: <http:/ / revistas.pucsp.br/ index. php/bakhtiniana/article/view/3373>. Acesso em: 18 fev. 2011.

LI M A, Regina Lúcia A lves de. Vozes em cena: análises das estratégias discursivas da mídia sobre os escândalos políticos. Belém: FAD E SP, 2010a. 156 p.

Da pauta à veiculação das notícias, o posicionamento dos jomais paraenses nas eleições municipais de 2004. In: AMARAL FILHO, Otacílio; CASTRO-

176

Ver a E ducação, v. 12, n. 1, p. 159-182, jan./ jun. 2011 
HORÁCIO, Fábio Fonseca; SEIXAS, Netilia Silva dos Anjos. (Org.). Pesquisa em Comunicação na Amazônia. Belém: FADESP, 2010b, p. 101-113.

LISBOA, Ingrid Valéria. A construção da violência urbana na Revista Veja. 2007. 228f. Dissertação (Mestrado em Comunicação e Semiótica) - Pontificia Universidade Católica de São Paulo. São Paulo, 2007. Disponível em: <http://bdtd.ibict.br; http://www.sapientia.pucsp.br//tde_busca/arquivo.php? $\operatorname{cod} A$ rquivo $=4309>$. A cesso em: 14 fev. 2011.

LYRA, A ndréa V irgínia Lamêgo. 0 vermelho da cultura do papel: a visibilidade midiática do MST e a imprensa. 2010. 133 f. Dissertação Mestrado em Cultura e Sociedade). Universidade Federal da Bahia. Bahia, 2010. D isponível em: $<$ http://bdtd.ibict.br; http://www.bibliotecadigital.ufba.br/tde_busca/arquivo. phprcodArquivo=3482> . Acesso em: 14 fev. 2011.

MACHADO, Marcia Benetti; JACKS, Nilda. O discurso jornalístico. In: Encontro Anual da Associação Nacional dos Programas de Pós-Graduação em Comunicação (Compós), 10. 2001. Brasília: ANAIS (eletrônicos). Compós, 2001. Disponível em: <http://www.compos.org.br; http://www.compos.org.br/data/biblioteca_1217. pdf>. Acesso em: 18 fev. 2011.

MACHADO, Rosa Helena Blanco. A palavra do outro e seus percursos na formação ideológica dos homens. Estudos da Lingua(gem). Vitória da Conquista, v. 5, n. 2, p. 75-92, dez. 2007. Disponivel em: <http:/ estudosdalinguagem.org/seer/ index.php/estudosdalinguagem/article/view/80/199>. Acesso em 18 fev. 2011.

M A K SU D, I via. Sexualidade e mídia: discursos jornalísticos sobre o "sexual" e a vida privada. Psicologia em Estudo, Maringá, v. 13, n. 4, p. 663-671, out./dez.2008. Disponivel em: <http://www.scielo.br/pdf/pe/v13n4/v13n4a04.pdf>. Acesso em: 18 fev. 2011.

MARTINS, André Ricardo Nunes. Grupos excluídos no discurso da mídia: Uma análise de discurso crítica. DELTA. São Paulo, v. 21, n. Especial, p. 129-147, 2005. Disponível em: <http://www.scielo.br/pdf/delta/v21nspe/29255.pdf>. Acesso em: 18 fev. 2011.

MATHEUS, Letícia Cantarela. Mediações jornalísticas do tempo - narrativas, periodicidade e produção de sentido histórico. Encontro da Associação Nacional dos Programas de Pós-Graduação em Comunicação (Compós), 18. 2009. Belo Horizonte (MG). ANAIS [eletrônicos]. Belo Horizonte: Compós; PUC-MG, 2009. Disponivel em: <http://www.compos.org.br/data/biblioteca_1131.pdf>. A cesso em: 18 fev. 2011.

MEDEIROS, Caciane Souza de. Sociedade da imagem: a (re) produção de sentidos da mídia do espetáculo. 2010. 173 f. Tese (Doutorado em Letras) - Universidade Federal de Santa M aria. Santa M aria (RS), 2010. D isponível em: <http:/ / cascavel. cpd.ufsm.br/tede/tde_busca/arquivo.php?codArquivo=3448>. Acesso em: 14 fev. 2011. 
MENDES, Patrícia Monteiro Cruz. Dos contornos do corpo às formas do eu: a construção de subjetividade femininas na revista "Sou+E u!". 2010. 123 f. Dissertação (Mestrado em Comunicação) - Universidade Federal da Paraíba, João Pessoa, 2010. Disponivel em: <http://bdtd.biblioteca.ufpb.br/tde_busca/arquivo. php?cod Arquivo=787>. Acesso em: 14 fev. 2011.

MORAIS, Fernanda Beatriz Caricari de. As mulheres na política brasileira: um estudo sob a perspectiva sistêmico-funcional. 2010. 133 f. D issertação (M estrado em Linguística A plicada e Estudos da Linguagem) - Pontifícia Universidade Católica de São Paulo. São Paulo, 2008. Disponível em: <http://www.sapientia. pucsp.br//tde_busca/arquivo.phprcod Arquivo=7581>. Acesso em: 14 fev. 2011.

MORGADO, Valdoméria Neves de M. O discurso educacional no artigo de opinião: o controle do já controlado. 2010. 144f. D issertação (M estrado em Letras e Linguística) - Universidade Federal de Goiás. Goiânia, 2010. Disponível em: <http://bdtd.ufg.br/tedesimplificado/tde_busca/arquivo. phprcodArquivo=1766>. Acesso em: 14 fev. 2011.

NASCIMENTO, Marilza Nunes de Araújo; RODRIGUES, Marlon Leal. O Discurso das Cotas na Mídia. Web-Revista Página de Debate: Questões de Linguística e Linguagem, n. 13, fev. 2010. D isponível em: <http:/ / www.cepad. net.br/linguisticaelinguagem/EDICOES/13/13.htm>. Acesso em: 18 fev. 2011.

NAVARRO, Luis H. Navarro. Enfrentando la violencia en las escuelas: un informe de Chile. In: ABRAMOVAY, Miriam (Coord.). Violência na escola: América Latina e Caribe. Brasília: UNESCO, 2003, p. 209-250.

NJAINE, Kathie; MINAYO, Maria Cecília de Souza. Análise do discurso da imprensa sobre rebeliões de jovens infratores em regime de privação de liberdade. Ciência e Saúde Coletiva. Rio de Janeiro, v. 7, n. 2, p. 285-297, 2002. Disponivel em: <http://www.scielo.br/pdf/csc/v7n2/10248.pdf>. Acesso em: 18 fev. 2011.

OLIVEIRA, Ana Claudia Mei A. de. A dupla expressão da identidade do jornal. Encontro da Associação Nacional dos Programas de Pós-Graduação em Comunicação (Compós), 15. 2006. Bauru (SP). ANAIS [eletrônicos]. Bauru: Compós; UNESP, 2006. <http://www.compos.org.br/data/biblioteca_501.pdf>. A cesso em: 18 fev. 2011.

OLIVEIRA, Edson Correia de. O discurso da notícia e a representação da identidade de gênero feminino nos crimes passionais. 2010. 255 f. Tese (D outorado em Língua Portuguesa) - Pontifícia Universidade Católica de São Paulo. São Paulo, 2010. Disponivel em: <http://www.sapientia.pucsp.br//tde_busca/arquivo. phprcodArquivo=10617>. Acesso em: 18 fev. 2011.

OLIVEIRA, Luiza R. et al. A divulgação científica de temas de saúde: análise de um impresso. Ciência em Tela, Rio de Janeiro, v. 3, n.1, 2010. Disponível em: $<$ http://www.cienciaemtela.nutes.ufrj.br/artigos/0110_oliveira.pdf $>$. Acesso em: 18 fev.2011.

178

Ver a E ducação, v. 12, n. 1, p. 159-182, jan./ jun. 2011 
ORTEGA, Rosario. O projeto de Sevilha contra a violência nas escolas: um modelo de intervenção educacional de natureza ecológica. In: DEBARBIEUX, Éric; BL,AYA, Catherine (Org.). Violência nas escolas: dez abordagens europeias. Brasília: UNESCO, 2002, p.197-222.

PE D RO SA, Jasson M atias. Violência, mídia e juventude: análise sobre o discurso adotado pelo jornalismo impresso sobre a realidade violenta de jovens da periferia da cidade de Natal. 2008. 93 f. Dissertação (Mestrado em Ciências Sociais) Universidade Federal do Rio Grande do Norte. Natal (RN), 2008. Disponível em: <http://bdtd.bczm.ufrn.br/tedesimplificado//tde_busca/arquivo. phprodArquivo=1977>. Acesso em: 18 fev. 2011.

PEREIRA, Ariane Carla; MACEDO, Márcio; I IEINZ, Norbert. A Amazônia, uma capa, um anúncio e três leituras. In: Congresso de Ciências da Comunicação da Região Sul, 10. 2009, Blumenau (SC). ANAIS [eletrônicos]. São Paulo: Intercom, 2009. CD-ROM. Disponível em: <http://www.intercom.org.br/papers/regionais/ sul2009/index.htm>. Acesso em: 18 fev. 2011.

PERUZZOLO, Adair C.. Estratégias sob a imagem. In: Congresso Brasileiro de Ciência da Comunicação, 14. 2001. Campo Grande (MS). ANAIS. São Paulo: Intercom, 2001, v. 24. p. 10-24.

PIRES, Cecília. A violência no Brasil. São Paulo: Moderna, 1985.

PONTES, Reinaldo Nobre. Violência nas escolas. In: __ Relações sociais e violência nas escolas. Belém (PA): Unama, 2007.

RAMALHO, Viviane Cristina Vieira Sebba. O discurso da imprensa brasileira sobre a invasão anglo-saxônica ao I raque. 2005. 194 f. D issertação (M estrado em Linguística) - Universidade de Brasília. Brasília, 2005. D isponível em: <http:/ / bdtd.bce.unb.br/tedesimplificado/tde_busca/arquivo.php?cod Arquivo=2297>. A cesso em: 14 fev. 2011.

RANGEL-S, Maria Lígia. Epidemia e Mídia: sentidos construídos em narrativas jornalísticas. Saúde e Sociedade. São Paulo, v. 12, n. 2, p. 5-17, jul.-dez. 2003. Disponivel em: <http://www.scielo.br/pdf/sausoc/v12n2/02.pdf $>$. Acesso em: 18 fev. 2011.

RIBEIRO, Tatiana W; PERGHER, Nicolau K.; TOROSSIAN, Sandra D. Drogas e adolescência: uma análise da ideologia presente na mídia. Psicologia: Reflexão e Crítica, Porto Alegre, v. 11, n. 3, p. 421-430, 1998. Disponível em: <http:// wwww.scielo.br/scielo.php?pid $=$ S0102-79721998000300003\&script=sci_arttext $>$. A cesso em: 18 fev. 2011.

RODRIGUES, Adriano Duarte. A Comunicação Social - noção, história, linguagem. Lisboa: E ditorial Vega, 1980.

SANTOS, Sidnay Fernandes dos. Dizeres sobre corrupção na mídia impressa brasileira: uma leitura discursiva. 2010. 121 f. D issertação (Mestrado em Linguística) - Universidade Federal de São Carlos, São Carlos, 2010. Disponível 
em: <http://www.bdtd.ufscar.br/htdocs/tedeSimplificado//tde_busca/arquivo. php? codArquivo=3168>. Acesso em: 14 fev. 2011.

SERRA, Giani Moliari Amaral; SANTOS, Elizabeth Moreira dos. Saúde e mídia na construção da obesidade e do corpo perfeito. Ciência e Saúde Coletiva, São Paulo, v. 8, n.3, p. 691-701, 2003. Disponível em: <http://www.scielo.br/pdf/ csc/v8n3/17450.pdf>. Acesso em: 18 fev. 2011.

SE RRA, Sônia. Relendo o "gatekeeper": notas sobre condicionantes do jornalismo. Contemporânea Revista de Comunicação e Cultura. Salvador, v. 2, n. 1, p. 93113, jan.-jun.2004. D isponível em: <http:/ / www.portalseer.ufba.br/ index.php/ contemporaneaposcom/article/download/3431/2499>. Acesso em: 18 fev. 2011.

SILVA, Luciana Kraemer. Entre o público e o privado: interpretações sobre estórias de abuso sexual em narrativas jornalísticas. 2008. 225f. D issertação (M estrado em Ciências Sociais) - Pontificia Universidade Católica do Rio Grande do Sul. Porto Alegre (RS): PUC-RS, 2008. Disponivel em: <http://tede.pucrs.br/tde_busca/ arquivo.php?codArquivo=1563>. Acesso em: 14 fev. 2011.

SILVA, Luciano Alfonso da. Personalização como estratégia discursiva do jornalismo: o caso da Fundação Iberê Camargo. 2010. 174 f. Dissertação (Mestrado em Comunicação e Informação) - Universidade Federal do Rio Grande do Sul. Porto Alegre (RS), 2010. D isponível em: <http:/ / www.lume.ufrgs.br/ handle/10183/24668> Acesso em: 14 fev. 2011.

SILVA, Luiz Martins. Por que a imprensa erra? 100 casos e algumas hipóteses. In: Encontro Anual da Associação Nacional dos Programas de Pós-Graduação em Comunicação (Compós), 10. 2001. Brasília. ANAIS [eletrônicos]. Compós, 2001. Disponível em: <http://www.compos.org.br/data/biblioteca_1223.pdf>. A cesso em: 18 fev. 2011.

SI LVA, L ivia Sousa da. 0 fenômeno bullying e o cenário escolar: numa perspectiva de garantia de direitos. 2010. 107 f. Monografia (Especialização em Psicologia E ducacional com ênfase em Psicopedagogia preventiva) - U niversidade do E stado do Pará (UE PA), Belém, 2010.

SILVA, Luciana Soares da. A metáfora conceptual na construção do discurso jornalístico. 2008. 149 f. D issertação (M estrado em Língua Portuguesa) - Pontifícia Universidade Católica de São Paulo. São Paulo, 2008. Disponivel em: $<$ http:// www.sapientia.pucsp.br//tde_busca/arquivo.phprcodArquivo=7714>. Acesso em: 14 fev. 2011.

SILVA, Maria da Conceição Fonseca. Memória discursiva, midia e efeitos de sentido da corrupção no Brasil. In: Congtesso Internacional da Associação Brasileira de Linguística (Abralin), 7. 2011, Curitiba. ANAIS [eletrônicos]. Curitiba (PR): ABRALIN, 2011, p. 2949-2956. CD-ROM. Disponivel em: < http://wwwabralin. org/abralin11_cdrom/artigos/Maria_da_Conceicao_Fonseca_Silva_1.PDF>. A cesso em: 18 fev. 2011.

180

Ver a E ducação, v. 12, n. 1, p. 159-182, jan./ jun. 2011 
SILVA, Maria do Carmo Soares Costa. Inclusão e deficiência: em busca das representações sociais na mídia impressa em Natal/RN. 2007. 170 f. Tese (Doutorado em Educação) - Universidade Federal do Rio Grande do Norte. Natal (RN), 2007. Disponível em: <http://bdtd.bczm.ufrn.br/tedesimplificado// tde_busca/arquivo.php?cod Arquivo=1195>. Acesso em: 14 fev. 2011.

SI LVA, M árcia Pinheiro da. Regularidades discursivas enquadradas nas primeiras páginas dos jornais: "O Diário" e "Hoje Maringá". Monografia (Graduação/ Licenciatura em Letras) - U niversidade Estadual de Maringá. M aringá (PR), 2008. D isponível em: <http:/ / www.gepomi.com.br/ producoes-academicas/ resumo/8>. Acesso em: 18 fev. 2011

SILVA, Simone Bueno da. A construção do corpo na mídia semanal. 2007. 119 f. Dissertação (Mestrado em Comunicação e Semiótica) - Pontificia Universidade Católica de São Paulo, São Paulo, 2007. Disponível em: <http://www.sapientia. pucsp.br//tde_busca/arquivo.phprcod Arquivo=5816>. Acesso em: 14 fev. 2011.

SILVEIRA, Juliana da; PASSET'TI, Maria Célia Cortez. Efeitos de (Im)parcialidade em Manchetes de Jornais Maringaenses, nas eleições municipais de 2004. In: FERNANDES, Cleudemar Alves Fernandes... [et al.]. (Org:). Análise do discurso: perspectivas. Uberlândia (MG): EDUFU, 2007, p. 544-555.

SOUZA, Andrea Carolina Veras Oliveira Pereira de. Violência, mídia e velhice: o idoso nas páginas policiais de Pernambuco. 2009. 88f. D issertação (M estrado em Gerontologia) - Pontifícia Universidade Católica de São Paulo. São Paulo, 2009. Disponivel em: <http://www.sapientia.pucsp.br//tde_busca/arquivo. phprcodArquivo=10507>. Acesso em: 14 fev. 2011.

SOUZA, Jefferson Barbosa de. O discurso midiático no fogo cruzado entre grupos transgressores organizados e equipes de segurança nacional: balas perdidas ou tiros certeiros? 2008. 110 f. D issertação (M estrado em Letras) - U niversidade Federal de Mato Grosso do Sul. Três Lagoas (MS), 2008. Disponível em: <http://www. cbc.ufms.br/tedesimplificado/tde_busca/arquivo.php?codArquivo=373>. Acesso em: 14 fev. 2011.

SOUZA, Lillian Bento de. A cobertura do caso Calabresi na mídia impressa e o conflito entre o infante exposto e o sujeito de direitos. 2009. 208 f. Dissertação (Mestrado em Comunicação) - Universidade Federal de Goiás, Goiânia, 2009. Disponivel em:; <http://bdtd.ufg.br/tedesimplificado/tde_busca/arquivo. phprcodArquivo=1230>. Acesso em:18 fev. 2011

SPOSITO, M arilia P. U m breve balanço da pesquisa sobre violência escolar no Brasil. Educação e Pesquisa, São Paulo, v.27, n.1, p. 87-103, jan./jun. 2001.

SWAIN, Tania Navarro. Feminismo e recortes do tempo presente. São Paulo em Perspectiva, São Paulo, v. 15, n. 3, p. 67-81, 2001. Disponivel em: http://www. scielo.br/ pdf/ spp/ v15n3/ a10v15n3.pdf Acesso em: 18 fev. 2011. 
TAMANINI-ADAMFS, Fátima Andréia J. Análise polifônica de estereótipos na mídia: uma nova identidade para a mulher na maturidade? 2010. 214 f. D issertação (M estrado em Letras) - U niversidade Federal de Santa Maria. Santa Maria, 2010. Disponivel em: <http://cascavel.cpd.ufsm.br/tede/tde_busca/arquivo. php?codArquivo=3174>. Acesso em: 18 fev. 2011 .

TOMITA, N ilce E my; PAD ULA, N iura Aparecida de M. R. Intoxicação por chumbo em crianças e o discurso da imprensa. Ciência e Saúde Coletiva, Rio de Janeiro, v. 10, n. Suplem., p. 561-569, set./ dez.2005. D isponível em: <http:/ / www. scielosp.org/scielo.php?pid $=\$ 1413-81232005000500014 \&$ script $=$ sci_arttext $>$. A cesso em: 18 fev. 2011.

TRAQUINA, Nelson. Quem vigia o "quarto poder"? In: Encontro A nual da Associação Nacional dos Programas de Pós-Graduação em Comunicação (Compós), 9. 2000. Porto Alegre (RS). ANAIS [eletrônicos]. Compós, 2000. Disponível em: <http://www.compos.org.br/data/biblioteca_1431.pdf>. Acesso em: 18 fev. 2011.

TRIN DADE, K elly Alessandra. M ecanismos discursivos e a representação da feminilidade e espiritualidade em artigos da revista Claudia. 2007. $165 \mathrm{f}$. Dissertaça (Mestrado em Língua Portuguesa) - Pontifícia Universidade Católica de São Paulo. São Paulo, 2007. Disponivel em: <http://www.sapientia.pucsp.br//tde_busca/ arquivo.php?codArquivo=5529>. Acesso em: 14 fev. 2011.

VIEIRA, Suellen; PEREIRA, Ariane Carla. Inclusão Social através do jornal: o discurso da deficiência e as deficiências do discurso. In: Congresso Brasileiro de Ciências da Comunicação, 23. 2010, Caxias do Sul (RS). ANAIS [eletrônicos]. São Paulo: Intercom, 2010. CD-ROM. Disponível em: <http://www.intercom.org. br/papers/nacionais/2010/resumos/R5-1084-1.pdf>. Acesso em: 18 fev. 2011.

WANDSCHEER, Lisiane. Análise da cobertura jornalística do crime organizado nos jornais Folha de São Paulo e O Globo com base no jornalismo para a paz. 2008. 160 f. Dissertação (Mestrado em Comunicação Social) - Pontifícia Universidade Católica do Rio Grande do Sul (PUC-RS). Porto Alegre, 2008. Disponivel em: $<$ http://tede.pucrs.br/tde_busca/arquivo.php?codArquivo=1348>. Acesso em: 18 fev. 2011.

WOLF, Mauro. Teorias da Comunicação. Lisboa: Editorial Presença, 1999.

ZANON, Leonardo Cordeiro. Mídia e discurso: um estudo do discurso da veja sobre o funk carioca. 2009. 108f. Dissertação (Mestrado em Comunicação Social) - Universidade Metodista de São Paulo. São Bernardo do Campo (SP), 2009. Disponivel em: $<$ http:/ ibict.metodista.br/tedeSimplificado/tde_busca/arquivo. phprcodArquivo=2043>. Acesso. 18 fev. 2011. 